\title{
Challenges and Potentials of Integrating Information Communication Technologies (ICTs) in Teacher Education Programs in Delta State University, Abraka, Nigeria
}

\author{
Obeten Obi Ekabua \\ Department of Computer \\ Science, \\ Delta State University, Abraka, \\ Nigeria
}

\author{
Nicholas Oluwole Ogini \\ Department of Computer \\ Science, \\ Delta State University, Abraka, \\ Nigeria
}

\author{
Noah Oghenefego \\ Ogwara \\ Department of Computer \\ Science, \\ Delta State University, Abraka, \\ Nigeria
}

\begin{abstract}
Information and Communications Technology or (ICT) encompasses telecommunications, computers as well as necessary enterprise software, middleware, storage, and audio-visual systems, which enable users to access, store, transmit, and manipulate information. While much of the rhetoric about (and rationale for) using ICTs in education has focused on the potential for changing the teaching-learning paradigm, in practice, ICTs are most often used in education to support existing teaching and learning practices with new (and, it should be noted, often quite expensive)tools. While impact on student achievement is still a matter of reasonable debate, a consensus seems to have formed that the introduction and use of ICTs in education can help promote and enable educational reform, and that ICT is a useful tool to both motivate learning and promote greater efficiencies in education systems and practices. The main purpose of this article is to enlighten the readers on the barriers to technology integration in the developing world using Delta State University in Nigeria as a case study. A survey was conducted through analyzing related literature and questionnaires distribution to lecturers and students in the education departments of the institution. From the findings, it was concluded that the main barriers hindering the integration of ICTs include lack of access to technology, lack of teacher confidence and lack of skills. Some of the benefits that can be achieved from ICT integration include students and lecturers motivation, quality education, promoting learners autonomy and user confidence.
\end{abstract}

\section{Keywords}

ICT integration, Improving teaching, Interactive learning environments, ICT assess, ICT skills

\section{INTRODUCTION}

For the successful integration of ICTs in the classroom, curriculum, and any educational setting a predetermined process is required. Integration of ICTs enhances the quality of education by helping teachers in doing their jobs and by helping students to learn more effectively. Teachers need to take the front role in applying technology innovations to the teaching and learning process [Jung, 2005]. Universities in the developing world can learn a lot of valuable lessons from the best practices around the world. There is no formula for the successful integration of ICTs, but strong policies need to be formulated and proper planning has to be done for the integration of ICTs to be successful.
ICTs are a diverse set of technological tools and resources used to communicate and to create, disseminate, store and manage information. These technologies include the internet, computers, broadcasting technologies and telephony. The potential of each technology varies on how it will be used [Ron, 2003].

Educational systems are globally under a lot of pressure to adapt to innovative methodologies and communication technology [Tinio, 2003]. Therefore, teachers are expected to keep themselves abreast with innovations in the changing technology so as not to impart skills and knowledge only but facilitate the learning in a meaningful approach and with an innovative methodology for individuals and learners.

In this age a culture should be cultivated among students to constantly seek new information, to critically think, to take initiative and to have lifelong learning. There is need to formulate ICT policies to make this achievable. Some institutions in Nigeria have responded to these challenges to enable their students to adapt to change, inspire creativity and innovation and enhance their ability to apply knowledge and solve emerging problems with confidence [Strydom \& Thompson, 2005].

Despite the testimony from researchers around the globe that technology use is increasing in teaching and learning, technology use has not been fully diffused in Delta State University and it has not been integrated into the curriculum. A significant number of students and teachers in the education department are enthusiastic about integrating ICTs in the curriculum and teaching practices but quite a number are also hesitant about what the use of ICTs will do to the department [Singh \& Kaur 2004].

The main challenge faced by the university is to transform the curriculum teaching and learning process to provide students with the skills to function effectively [Goktas, Yildirim \& Yaildirim, 2009]. This is mainly because the authorities are not injecting capital to fund ICT projects within the department. Policies should also be formulated to support the integration of ICTs into the curricula and also in an in-house training [Nicholson, 2007].

Since we are now living in the information age, the university should prioritize the use of technology so that students may be well equipped with knowledge, skills and confidence to operate in the current environment. 
The issue of the use of technologies such as the internet is not an issue in the Delta State University since almost everyone can use the internet, rather the issue is how to effectively use these technologies in the education department so that both students and lectures can grab the opportunities offered by them and thus creating positive learning experiences [Nafiz, 2010].

The Delta State University is still in the infant stages of ICT adoption. This is evidenced by the lack of technical support, e-learning which is almost non-existent but is still under construction and the website which is not regularly updated. Lecturers in the education department have not yet fully incorporated the use of ICTs in their classroom; the only technology they use is the internet when conducting researches to plan for their lessons.

Integrating ICTs in the university will render its operations more profitable because ICTs enable the teacher to student ratio to increase. This can be achieved through video conferencing and e-learning where students can communicate with their lecturers online, assignments marked online and where lecturers can distribute study materials online.

Successful integration of ICTs in the Delta State University does not only require technology, but also curriculum and pedagogy, institutional readiness, teacher competencies and long term financing among others [Goktas, Yildirim \& Yaildirim, 2009].

\section{BENEFITS OF INTEGRATING ICTS IN EDUCATION.}

Numerous benefits are derived from integrating ICTs in the curriculum. Some advantages cited by various researchers include but are not limited to;

- Improves the quality of education by helping teachers to do their jobs and by helping students to learn more effectively [Anderson, 2002].

- Provides opportunities for students to learn to operate in information age [Strydom \& Thompson, 2005].

Some of the major advantages ICTs offer to students includes:

- ICTs provide quality learning. Students learn lifelong skills which they will use in their careers.

- ICTs promote active learning and critical thinking

- Offers diversity, self-paced learning and individual growth.

- $\quad$ Provides flexibility for students with special needs.

- Promotes cooperative learning and increases teacher student interaction.

- Motivates and inspires students by making learning exciting and relevant.

- A greater disposition to research and problem solving focused on real situations through simulations.

- Capacity to cope with rapidly changing, complex and uncertain environments.

\subsection{Obstacles in integrating ICTs}

Integrating ICTs into the education programs in a university is a gigantic task. Some researchers classify the barriers as system level, teacher level and school level barriers [Khalid, 2009], while others classify the barriers as only system level and teacher level [Nicholson, 2007], and others extrinsic and intrinsic. This research will mainly focus on the teacher level and school level barriers.

\subsubsection{Teacher level barriers}

These are barriers which relate to an individual teacher. The following are some of the teacher level barriers:

1. Lack of ICT skills: teachers do not use ICTs in their classrooms because they do not have the skills and hence are not confident in using them [Khalid, 2009]. Teachers who have little or no confidence in using computers will try to avoid them altogether [Goktas, Yildirim \& Yaildirim, 2009]. Fear of failure is one of the main reasons why teachers who lack ICT skills do not use them in their classes.

2. Resistance to change and negative attitudes: Most teachers who are not using ICTs believe that using them or not using them does not make a difference. Resistance to change seems not be a barrier itself but indicates that something is wrong [1Strydom \& Thompson, 2005]. This resistance is a factor which prevents the full integration of ICTs into the classroom [Goktas, Yildirim \& Yaildirim, 2009].

3. Inappropriate teacher training: Most teacher training programs fail to engage teachers in using ICTs because the training courses focus on development of ICT skills and not on the pedagogical aspects of ICTs [Khalid, 2009]. It is necessary to provide pedagogical training for teachers rather than simply training them to use ICT tools.

\subsubsection{School level barriers}

These barriers relate to the institutional context. These do not affect an individual but affects everyone involved in the school. Some of the school level barriers are explained below.

1. Lack of time: Teachers do not have enough time to use technologies in their classes. The aspects of ICTs which require more time include time needed to locate internet advice, prepare lessons, explore and practice using technology, deal with technical problems and receive adequate training [Strydom \& Thompson, 2005].

2. The absence and poor quality of ICT infrastructure: The availability of ICT infrastructure does not necessarily mean the successful integration of ICTs but its absence is a major hindrance to the successful integration in the university [18]. Hardware that is not properly maintained may cause problems to the delivery of lessons and inappropriate software does not help in any way. Technical faults are likely to lead to lower levels of ICT use by teachers [Goktas, Yildirim \& Yaildirim, 2009].

3. Lack of accessibility: If teachers have access to ICTs including at home they are most likely to use 
them in their classes. The inaccessibility of ICTs may be a result of one of the following: poor quality hardware, inappropriate software, and lack of personal access for teachers [Strydom \& Thompson, 2005]. As a result teachers and students will not have the opportunity of using ICTs at any time according to their needs.

4. Lack of appropriate administrative support: Schools face problems in integrating ICTs because they are not seen as part of the general strategies at the school [Khalid, 2009]

Some other barriers include: Lack of in-service training, lack of technical support, lack of experience in project based learning.

\section{STUDY}

This section reports on the findings of integration of ICTs into the classroom and curriculum and is drawn from a survey of 25 lecturers and 100 students from the school of education in the Delta State University. The education department sectors under consideration are the sciences, commercials and arts. Questionnaires were given to lecturers and students to investigate the way they view ICTs being integrated in the classroom and to test on their ICT skills. The outcome of the questionnaires will be clearly shown in the results.

\subsection{Findings}

The findings obtained from analyzing the questionnaires is hereby reported. The questions were grouped into eight different sections including skills survey, benefits of ICTs, barriers of ICTs, how frequently ICTs are used, status of ICTs and the effect of ICTs.

\subsubsection{Current status of ICT infrastructure in the education department}

Table 1. Current status of ICT infrastructure

\begin{tabular}{|l|l|l|}
\hline Subject area & $\begin{array}{l}\text { Number of } \\
\text { current students }\end{array}$ & $\begin{array}{l}\text { Number } \\
\text { computers }\end{array}$ \\
\hline Commerce & 345 & 40 \\
\hline Sciences & 392 & 40 \\
\hline Arts & 407 & 40 \\
\hline
\end{tabular}

Table 1 indicates that there are only 40 computers for all the students in the department. It is clear that the computer: student ratio is too high. Currently the computer laboratory is not functional which means that the students do not have any access to computers. The administration in the department should make a plan to at least make sure that students have access to the laboratory.

\subsubsection{Current status of ICT related courses in the existing Syllabus in the education department}

Table 2. Status of ICT related courses

\begin{tabular}{|l|l|l|}
\hline Subject area & Level & $\begin{array}{l}\text { ICT related courses in the } \\
\text { existing syllabus }\end{array}$ \\
\hline Commerce & 1 & No \\
\hline & 2 & No \\
\hline & 3 & 1 \\
\hline
\end{tabular}

\begin{tabular}{|l|l|l|}
\hline Sciences & 1 & No \\
\hline & 2 & No \\
\hline & 3 & 1 \\
\hline Arts & 1 & No \\
\hline & 2 & No \\
\hline & 3 & 1 \\
\hline
\end{tabular}

Table 2 indicates that computer related courses are offered to third year students only. For the complete integration of ICTs, computer related courses should be offered (at least one per year) to all students in this department. Because students are only introduced to technology in their final year of study, they will lack skills and confidence of teaching or integrating technology to their learners.

Of the 100 questionnaires distributed to students, 30 of the students are majoring in sciences (physical science and mathematics), 30 of them are majoring in commercials (accounting, economics) and 40 are majoring in arts subjects like psychology and sociology. $100 \%$ responses was obtained since the students were "ambushed" while having their lectures and given 20 minutes to respond.

The questionnaires were distributed evenly among the students. 50 questionnaires were given to female students and the other 50 questionnaires to male students.

Most of the students are between 20 to 29 years of age. 89 out of 100 are between 20-29 years old, seven are 30 to 39 years and four are 40 years and above. 30 questionnaires were handed to lecturers in the education department but, only 25 of the 30 lecturers responded to the questionnaire where 9 are female and 14 are male. Of the female five are between the ages of 30-39 years, two are in the 40-49 year age group, one is above 40 years and one is between 20 and 29 years.

Of the male lecturers, seven are in the age range of 30-39 years, four in the range 40-49 years, two in the 20-29 years age group and 1 is above 50.8 of the lecturers major in sciences, 10 major in commercials and 7 are majoring in arts.

\subsection{ICT access}

The survey reflected that most of the lecturers have their own personal computers provided by the university except for the junior lecturers who do not have their own offices. 3 out of the 25 lecturers do not have computers in their offices but of the 3, two have their own laptops.

$100 \%$ of the survey shows that there is no computer laboratory for the students. Postgraduate students use the postgraduate laboratory provided for all postgraduate students in the university. Only 20 out of the 100 students have their own desktop or laptop computers. 80 of the students do not have computers in their hostels or at home.

All the lecturers have access to computers on a daily basis except for the one lecturer who does not own a personal computer.

Since they do not have computer laboratories, the students do not have access to computers, except for the 20 who have their own computers. Access to computers is achieve only during the general university-wide course on introduction to ICT conducted in the computer science department. The students said most of the computers in that department are not working so they never have access unless you are early and get a machine which is working properly. 20 out of the 100 
students access their personal machines on almost a daily basis, 13 students said they never have access and 67 students said once a month.

\subsection{Acceptance of ICTs}

When asked if they are willing to incorporate ICTs as part of the curriculum, most of the lecturers were on the affirmative but a few especially the ladies had reservations.

Most of the students are enthusiastic about incorporating ICTs as part of the curriculum. 95\% of the students would like to see ICTs in full use at the university while only $5 \%$ are not sure that ICTs will be helpful to them.

To the question, "do you think ICTs can be incorporated as part of the curriculum?" Most of the students think that if the barriers are overcome then it can be done. 88 out of 100 students agree to this, 9 out of 100 students said maybe and 3 out of 100 students said no because they do not have confidence in the system.

When asked this same question 21 out of the 25 lecturers were on the affirmative and only 4 lecturers said maybe because they are not sure if this is achievable. As of now only third year students undertake an ICT course which introduces them to the basics of computers.

\subsection{Barriers of Integrating of ICTs}

The most commonly noted reason for not implementing a technology-integrated lesson was that necessary computers were not available (25 lecturers). The statistics of some of the other barriers include:

- $\quad 16$ out of 25 lecturers said teacher confidence

- $\quad 10$ out of 25 lecturers said school policies

- $\quad 11$ of the 25 lecturers chose technical support

- Teacher confidence was cited by 19 of the 25 teachers

- 9 over 25 lecturers said availability of internet and software. Connection to the internet is very slow in the department

- $\quad 11$ out of 25 lecturers mentioned technical support

Most of the female lecturers are the ones who mentioned teacher confidence as the reason why technology is not being integrated. All the lecturers above 40 also noted this point.

77 out of the 100 students mentioned teacher confidence as the reason why technology is not being integrated in the classroom. 11 over 100 students think financial constraints is the reason, 55 over 100 students chose technical support while $59 \%$ of the students said school policies. It is evident that the students do not really trust their lecturers when it comes to them integrating technologies as part of the curriculum.

\subsection{ICT use in classes}

The lecturers were asked if they had ever used ICTs in their classes either as an aid to what they were teaching or as a tool to teaching. The following are their responses:

- 25 out of 25 lecturers said they had used the internet in trying to research on the latest information to teach their students

- $\quad 9$ out of 25 lecturers said they used slide shows and projectors whilst conducting their lectures
- 14 out of 25 lecturers said they had not used anything else other than the internet.

Of the 9 over 25 lecturers, six are male and 3 are female and all of them in the 30-39 years age group.

Students were asked if they had ever had lecturers who presented their lessons using technology. The following are the students' responses:

- 31 out of 100 students agree that some of the lecturers use slide shows. 21 students are from the sciences department and 10 are from the commercials department. Everyone from the arts section noted that they have never had technology integrated lectures.

- The only time some of these students have experienced technology use is in the computer science department during their introduction course.

Most of the students said the lecturers who use technology do so at least once in six months.

For those lecturers who say they use technology in their classes, they were asked how many times they normally use technology. Almost all of them said once in six months.

To the question why they do not use technology in their classes, lecturers had the responses below:

- $100 \%$ lecturers said lack of access to resources

- 21 out of 25 of the lecturers said lack of time. They believe that they need time to learn how to use the resource and to research on the resource.

- $\quad 16$ out of 25 lecturers cited lack of skills

- 14 of the 25 participants believe that technology will not have an impact on their lectures.

- $\quad$ None of them said lack of internet access because they all have internet installed on their computers by the school. The only inconveniencing factor may be that the internet connection is very slow.

When asked about the challenges that were experienced whilst implementing technology-integrated lessons the most common responses lecturers gave included:

- Too few computers $(96 \%)$;

- Time constraints and hence lesson not completed (80\%);

- Learners did not have enough computer skills (40\%); and

- Difficulties with scheduling enough time (60\%).

Once again the access to computers is being "blamed" by the educators. Further research is needed to ascertain to what extent the lack of access is really the problem, or if other aspects are hindering the integration.

\subsection{Benefits of ICTs}

Most of the students believe that ICTs will prepare them for the modern world which is now using ICTs in every aspect of their lives. They also believe that ICTs will improve the quality of education and that when they become teachers, they will be able to use ICTs for their students and that they will gain confidence in using them.

Lecturers were also asked the same question on the benefits ICTs will bring to the department. 
- $19 / 25$ of the lecturers said more enthusiastic and alert students

- 24/25 lecturers said students who are able to compete in the current technology environment

- $\quad 25 / 25$ said quality students and quality education.

The lecturers were also asked to make suggestions on what they thought should be done to the department to improve on their ICT. Most of the noted suggestions include:

- Capital injection to start an ICT project from the school admin

- A computer laboratory for the third year students and post graduates to conduct their researches

- A training program for the lecturers in the department on how to integrate and incorporate ICTs in the curriculum.

\subsection{Effect of ICTs}

Some questions were designed to investigate how lecturers and students feel about the use of ICTs and what they think their effect will be.

Most of the lecturers believe they can do their work more effectively but not necessarily faster. Some of them admit that they have a hard time accessing the functions they need when using some of the applications.

To the same questions, the students had the following responses:

- $83 \%$ students said they can do their work more effectively and efficiently

- $\quad 77 \%$ students say they have problems with finding the functions they need ,

- $\quad 27 \%$ students know how to use the basic features of Microsoft office. Other than that they cannot do anything else.

\subsection{Skills related questions}

Some questions were designed and categorized into hardware and software questions to investigate the basic skills that both the students and lecturers possess. This will help in finding a way forward to the complete integration of ICTs.

\subsubsection{Software}

When asked the question, what application uses the file extension .mdb? The question proved to be difficult for both the lecturers and the students. The statistics are shown below:

- $18 / 25$ of the lecturer s said they are not sure of the answer

- $7 / 25$ lecturers attempted to answer the question of which only 5 got it correct.

- $93 / 100$ of the students were not sure

- $7 / 100$ students knew the correct answer

Of the seven students four were from sciences, two from commercials and one from the arts department. The researcher is not sure whether those who knew the answer were guessing or not.

Another question asked was about the feature that is used by Microsoft word to connect a web document to the internet. $100 \%$ of the respondents did not know the answer to this one. These results prove for themselves that most of the stakeholders in this department know how to use the basic features of Microsoft office packages and this may be the reason why some lecturers are reluctant to incorporate ICTs in the curriculum.

Given the options: graphics presentation, spread sheet and scheduler both lecturers and students were asked to tick what they have used before.

- $17 / 25$ of the lecturers said they have used spread sheets.

- 15/25 lecturers said they have used graphics presentation

- $5 / 25$ lecturers said they have used a scheduler (calendar program).

- $4 / 25$ lecturers have used all three programs.

The students gave the following answers:

- $23 / 100$ students said they have used a spread sheet before

- $20 / 100$ students said they have used a graphics presentation software

- $\quad 11 / 100$ students have used a scheduler

- $\quad 9 / 100$ students have used all three.

Lecturers were presented with some technologies and asked to tick what they have used before. These technologies include video conferencing, interactive white board, learning management systems and slide shows.

- 8/25 lecturers have used video conferencing especially Skype when communicating with their friends and family, but not using the school's resources.

- None of them have used interactive white board

- None of them have used learning management systems.

- 11/25 lecturers have used slide shows in their lectures, and $24 / 25$ had some experience of slide shows.

When asked to distinguish between some application packages and systems software most of the lecturers and the students could not accomplish this task.

- $87 \%$ of the students were not able to pick among given options which was an operating system.

- Only $13 \%$ of the students were able to choose windows XP. Most of the students were confusing it with internet explorer.

- $13 / 25$ of lecturers were able to pick among the options and 12/25 were not able to do it.

\subsubsection{Hardware}

Lecturers and students were asked to choose hardware objects among given options. All of the lecturers were able to pick the correct answer. $82 / 100$ of the students chose the correct answer.

Both students and lecturers were also asked to distinguish an input device from given options. 18/25 of the lecturers were 
able to choose the correct answer and 72/100 of the students were also able to choose the correct answer.

A basic maintenance question on how to clean a keyboard was also asked. Both lecturers and students did not know the answer to this one. $100 \%$ of the respondents said they are not sure of the answer.

\section{DISCUSSION}

In this section we will be discussing the findings reported in the study and represent them with diagrams and graphs to clearly illustrate the challenges being faced by the education department. Conclusions will be drawn from the diagrammatic and graphical illustrations.

\subsection{ICT access}

The university provides computers to the lecturers. Almost all the lecturers have their own desktop computers in their own offices. The graph below shows how computers are distributed among the lecturers in the department.

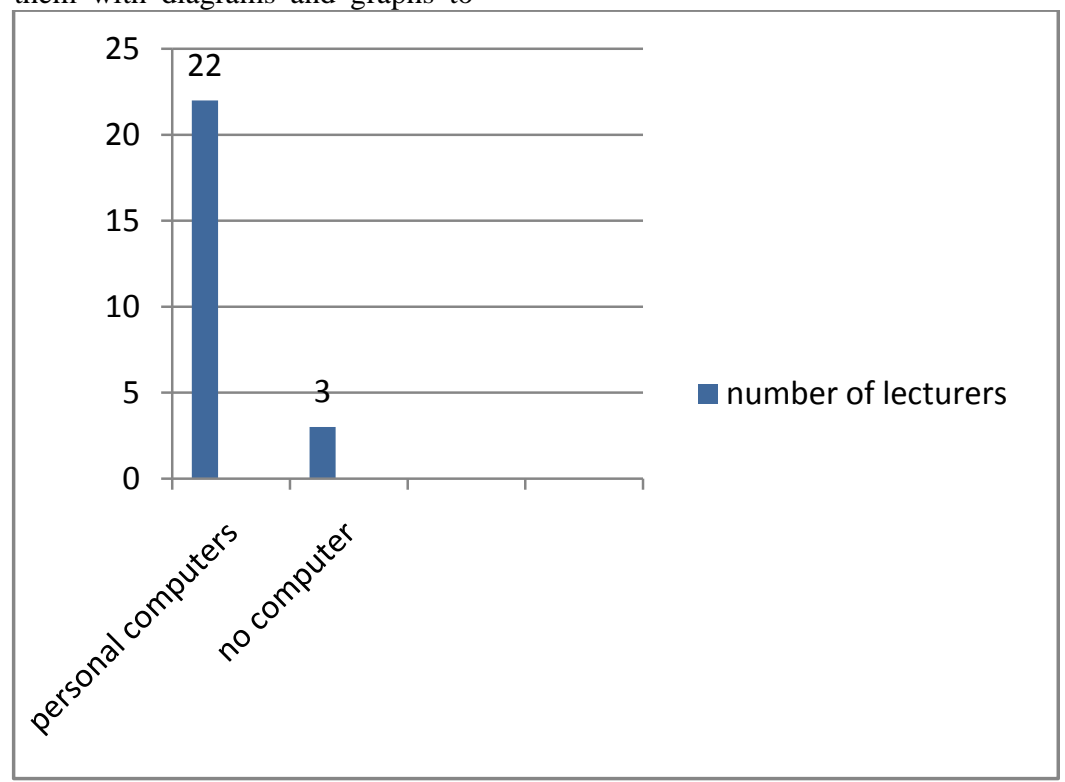

Fig. 1. Lecturers provided with computers by the university

The university provides computers for the lecturers which are required to be used for administrative purposes. This shows that the school of education is still in the "initial phase" of the
ICT integration process as suggested by UNESCO. The graph below shows computer access for students:

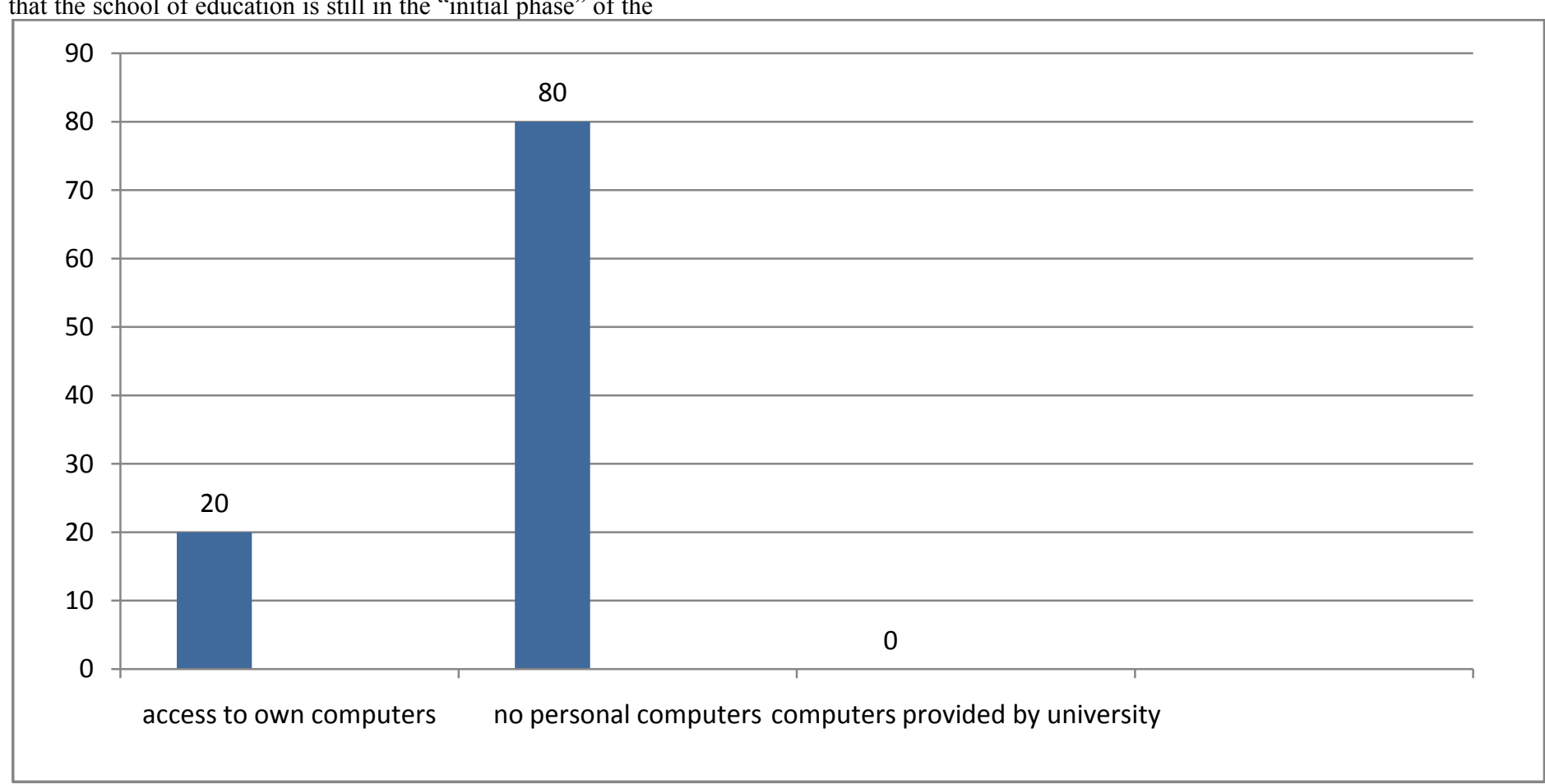

Fig. 2. Students' access to computers

Since the department has a dysfunctional laboratory for the students, we can conclude that it is not offering any access of computers to students. These results show that the department is still in the "initial stage" because only lecturers have 
access to computers and they only use them for research and administrative purposes. A lot still has to be done in terms of purchasing computers and the appropriate software to be used.
The ICT Unit has to make a financial plan of how to get these resources. The graph below shows the frequency of access to computers by both lecturers and their students.

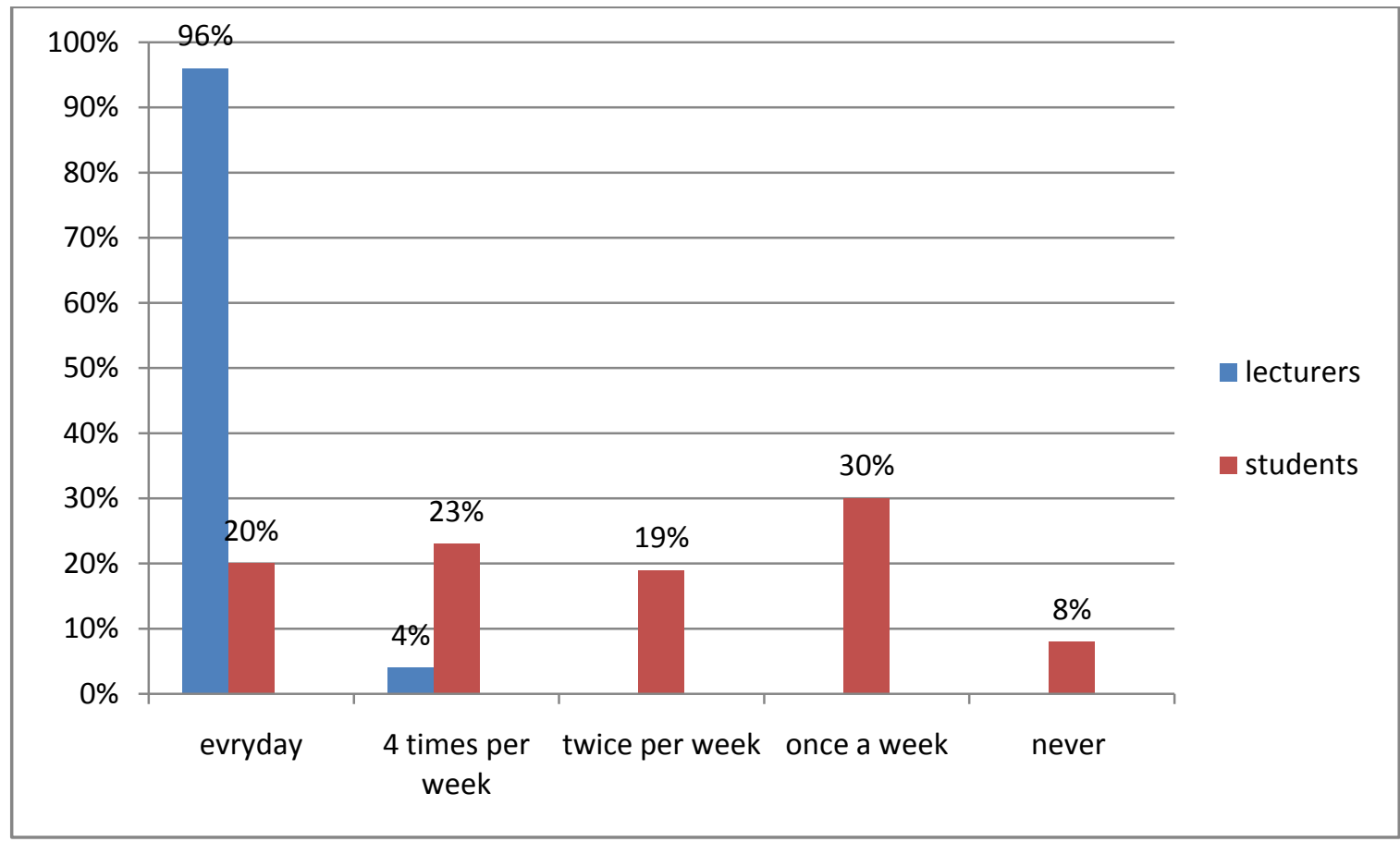

Fig. 3. Frequency of access to computers by both lecturers and students

The graph indicates that most lecturers have access to the computers on almost a daily basis. It is disappointing to see that students are struggling to get access to technologies in this information age. Teachers who leave the university will not use ICTs when they finish because they lack confidence and skills.

\subsection{ICT use in Classes}

All lecturers use the internet when researching and preparing for their lectures. Although they use the internet, very few of them have used technologies like slide shows, teleconferencing (e.g. video conferencing) and television. It is of importance to note that 8 of the female lecturers have implemented technology integrated lessons whilst 9 of the male have also implemented technology as shown in Fig. 4.

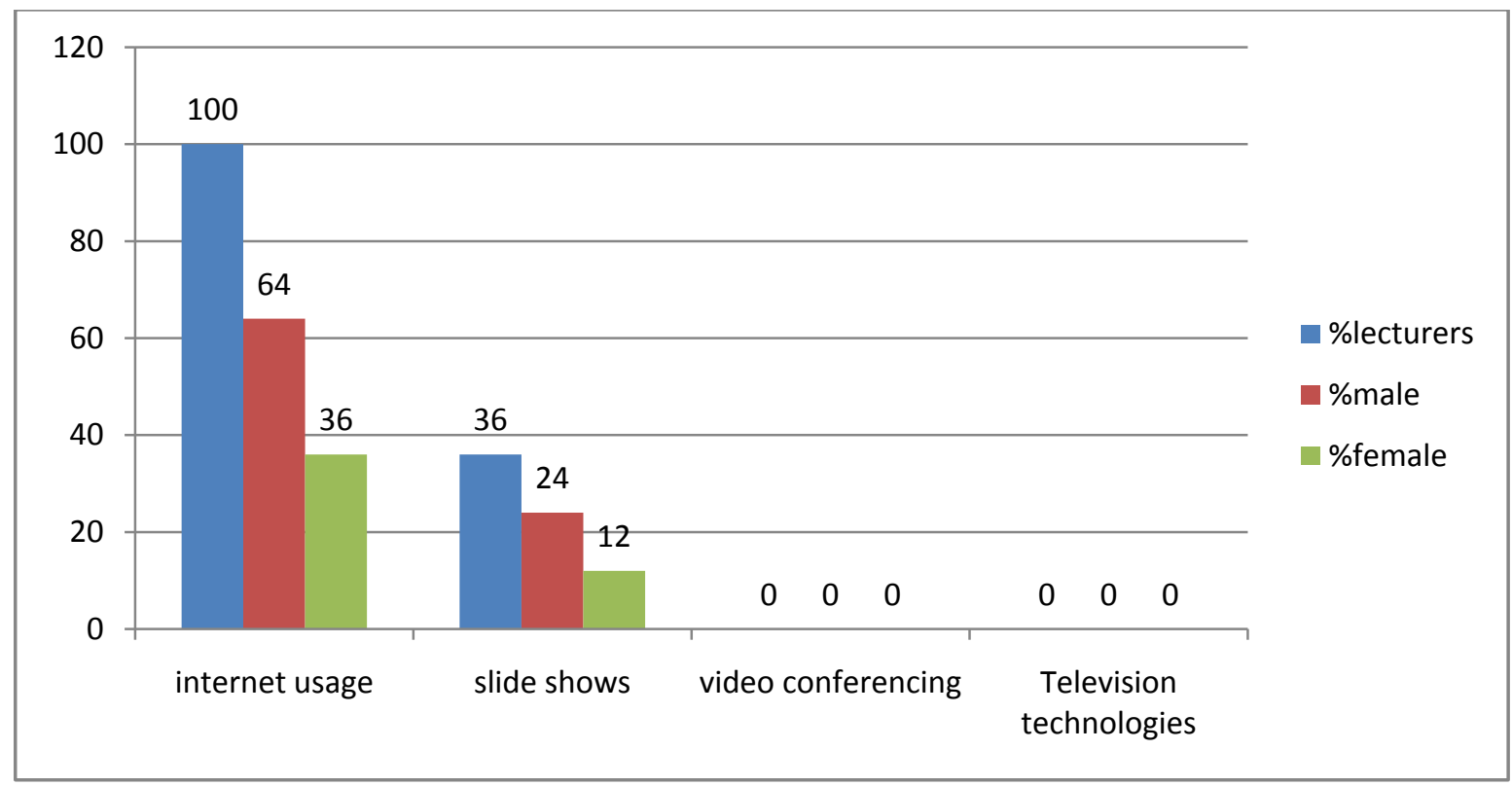

Fig. 4. Technologies that have been used in class 
This graph also indicates that the university is still in the initial phase but is also moving towards the application phase. Here, the lecturers were asked for the reasons why they find it difficult to integrate ICTs in their classes. The graph in Fig. 5 indicates what the lecturers pointed out as their main reasons for not incorporating ICTs.

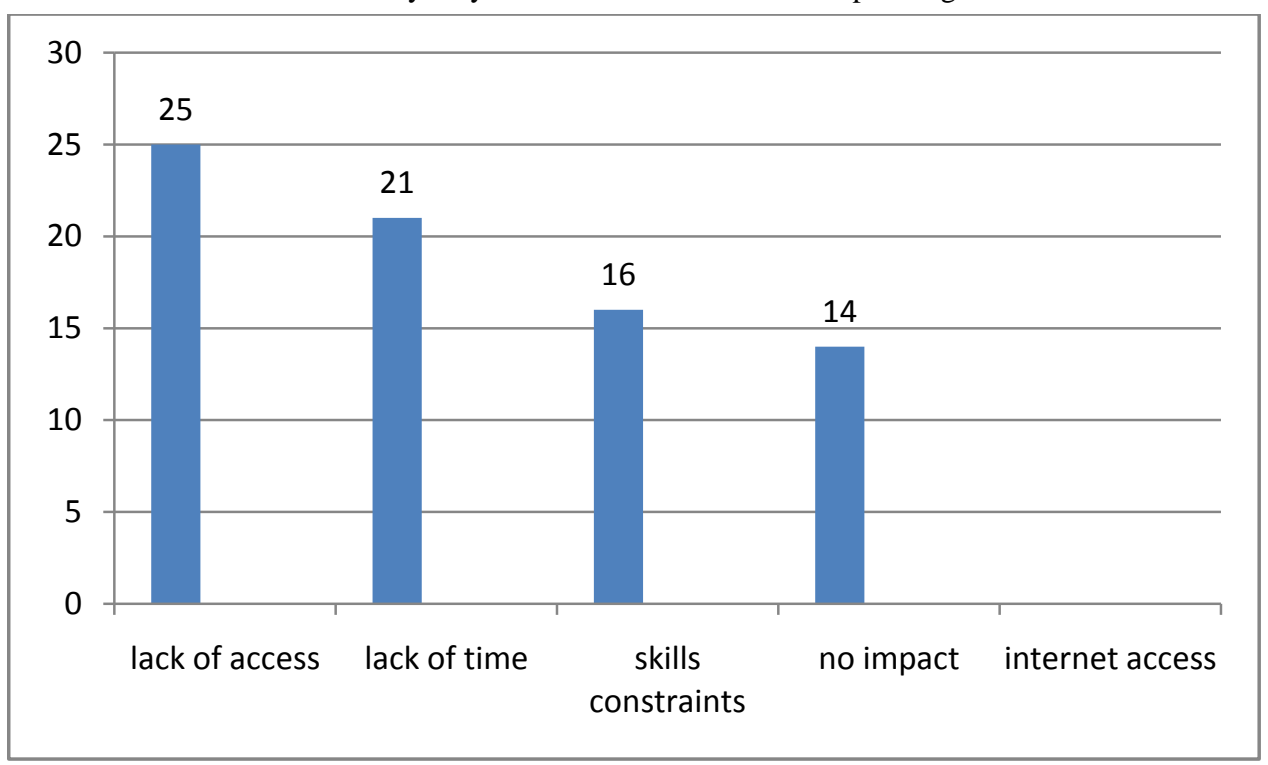

Fig. 5. Reasons for not integrating technologies in class

Lack of access to resources like video conferencing technology, projectors and TV technology has once again appeared as the number one factor why lectures are not using technology. The university has to invest some money into purchasing the right technology for this department so that both students and lecturers may be abreast with the changing technology. A number of lecturers have also mentioned lack of time to practice and research. It appears that Internet access at school is also not a sufficient condition to influence the implementation of technology-integrated lessons. None of the lecturers mentioned internet access, but it seems most are yet to conduct lectures with technology. Most of those who mentioned that technology will have no impact in their lessons and those who said skills constraints are assumed to be resistant to change.

\subsection{Benefits of ICTs}

Most of the lecturers and students are positive about the benefits ICTs will bring to the education department. Some of the benefits chosen from the options given and their frequencies are shown in Fig. 6 below.

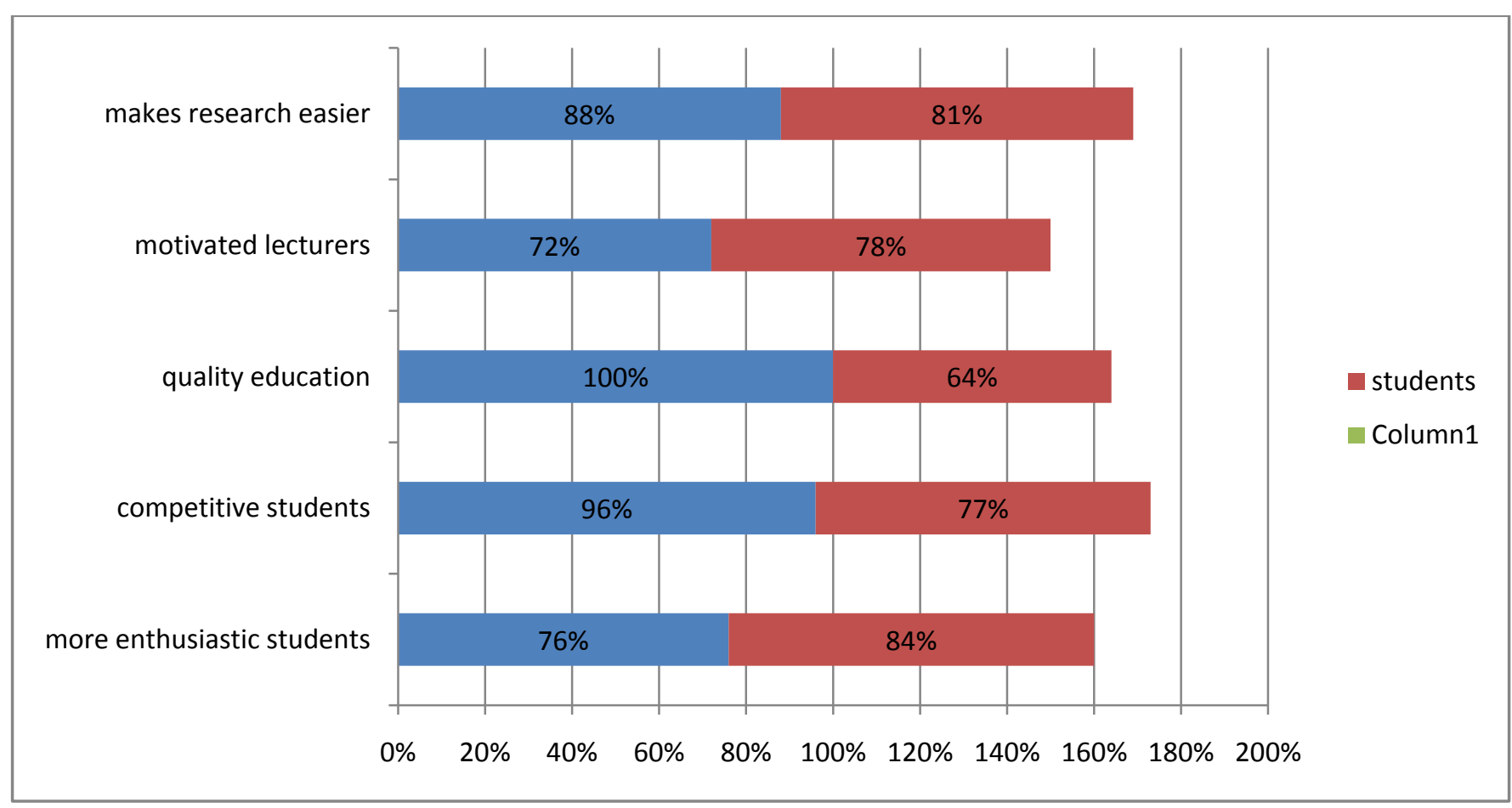

Fig. 6. Benefits of ICTs 
The graph in Fig. 6 indicates that most of the respondents are aware of the benefits of ICTs. This signifies that if they are to be introduced fully, most of the stakeholders will accept them.
An investigation was made to see the effect of ICTs with the current computer setup. Fig. 7 is an indication from the lecturers.

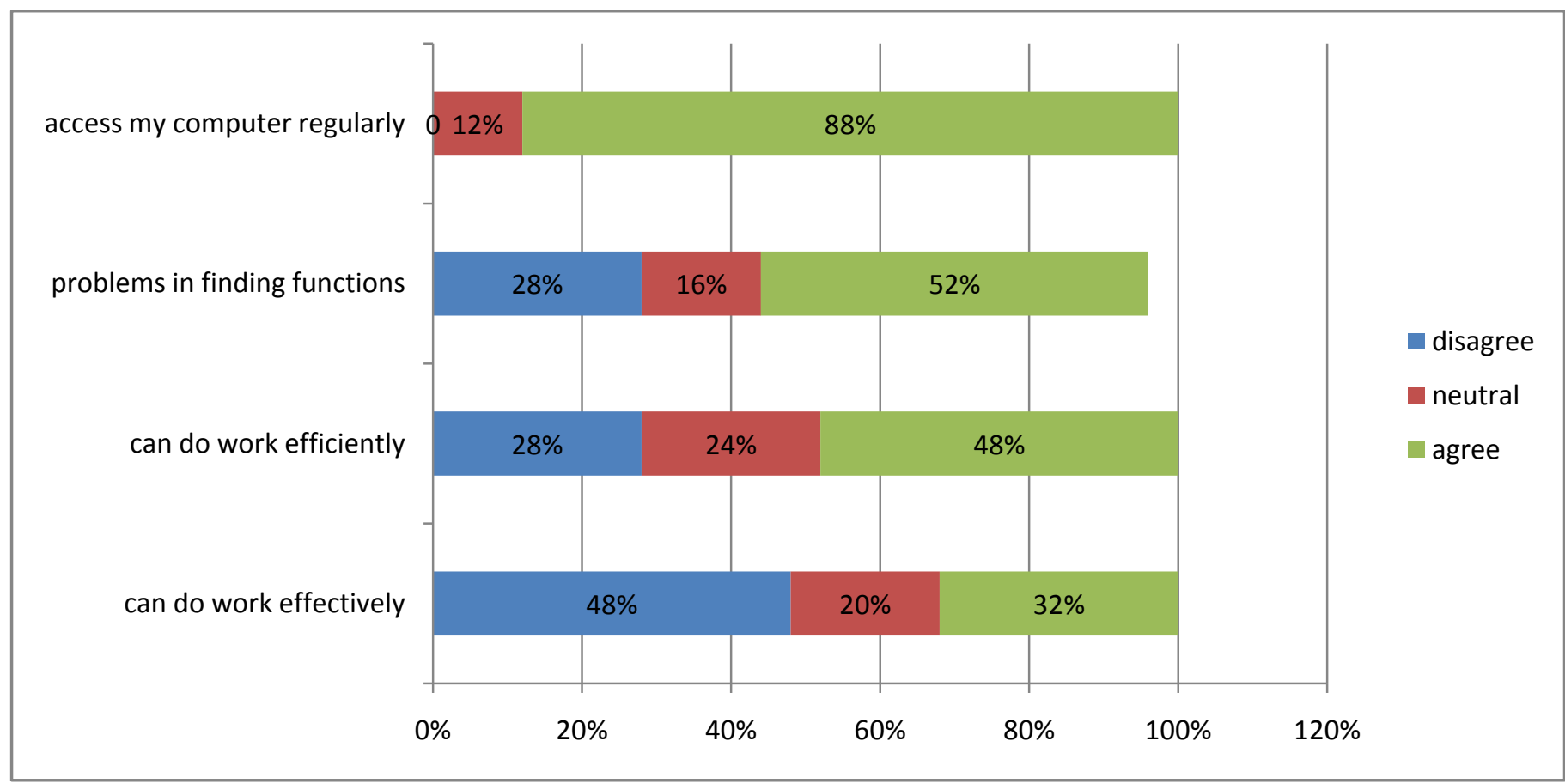

Fig. 7. Effects of current computer setup

The graph in Fig. 7 shows that most of the lecturers are still in need of training on how to use computers before they can start implementing them in their own classes. Even though they have access, it seems they mainly use them for surfing the internet and for other administrative work. Most of them agree that they can do work more effectively, but not faster. The graph also proves that having access to computers does not mean being able to use them in classes.

\subsection{Skills survey}

A lot of the lecturers have some experience in using Microsoft office packages but they have not really explored other technologies. Figure 8 below shows technologies that lecturers have had some experience with.

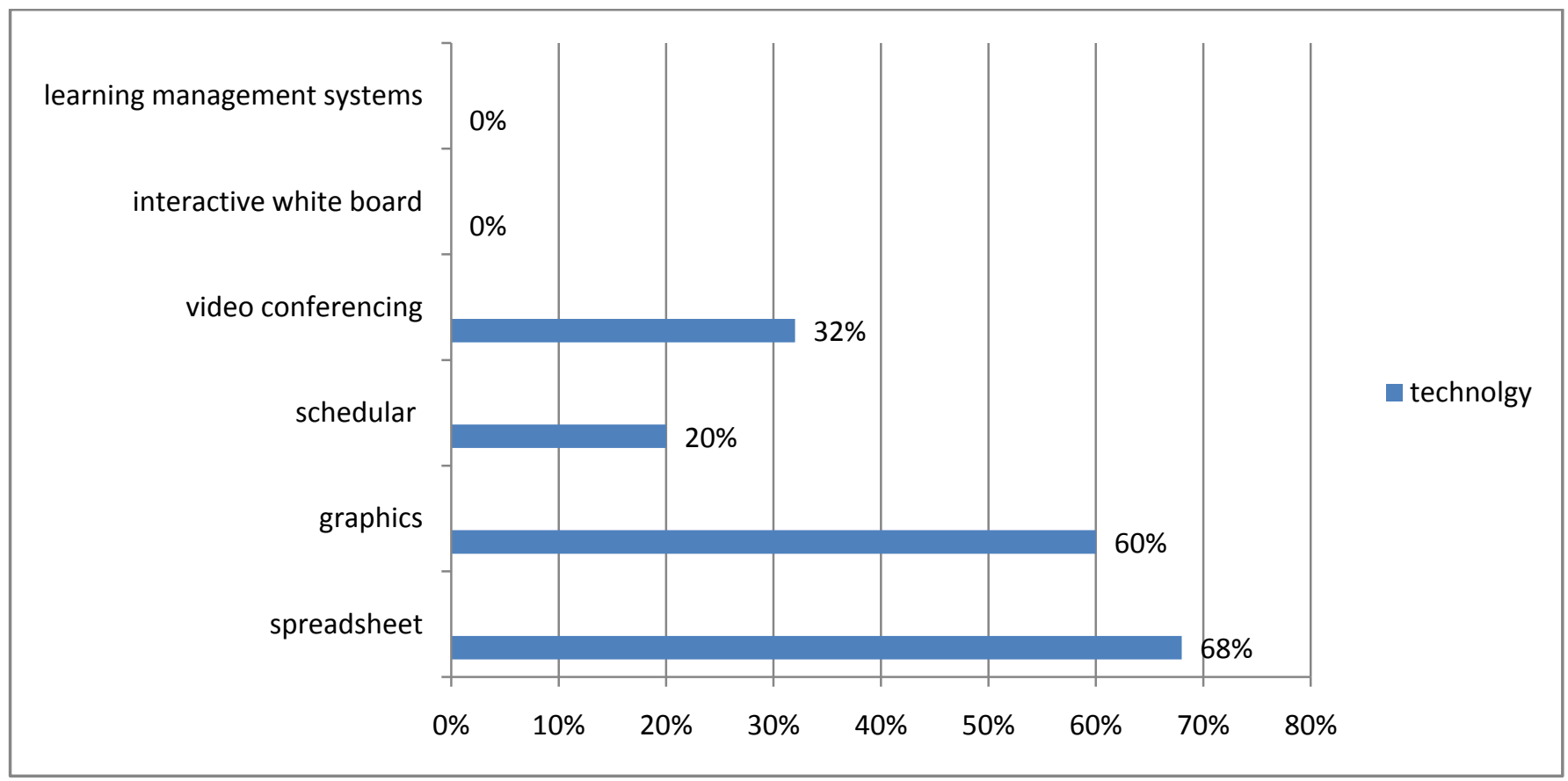

Fig. 8. Technologies that have been used by lecturers

From the evidence above in Fig. 8 we see that most lecturers have experience with packages that are mainly used for administrative work. None of the lecturers have used interactive white board and learning management systems. 
Very few of the lecturers have used teleconferencing technologies like video conferencing.
Students' statistics are shown in Fig. 9 below.

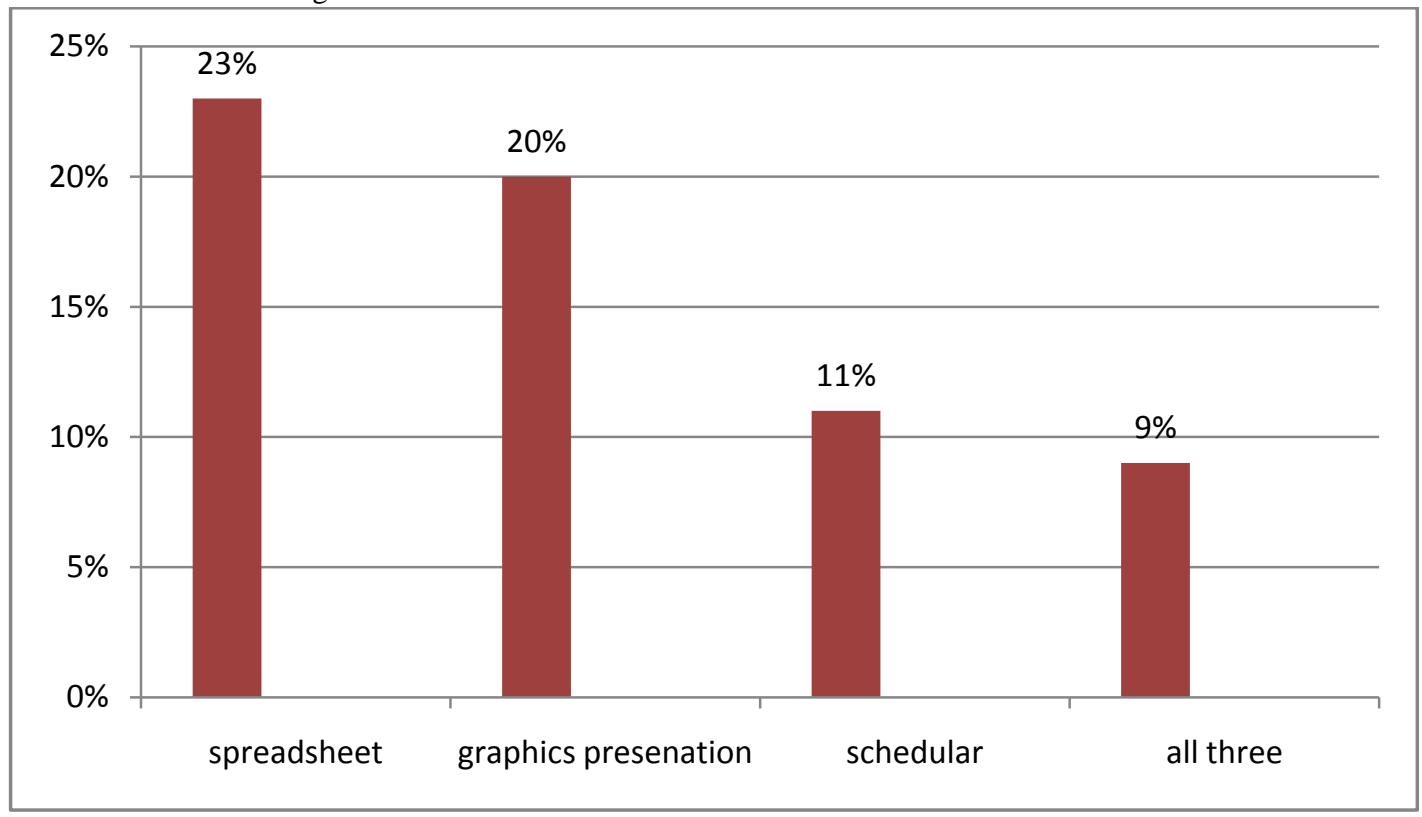

Fig. 9. Technologies used by students

It is noted that only $9 \%$ of the sampled students have used spread sheets, graphics presentation and schedulers, yet these are the common programs that everyone is supposed to know.
A research was made to determine the software level of competence of the respondents. Fig. 10 below indicates the results drawn.

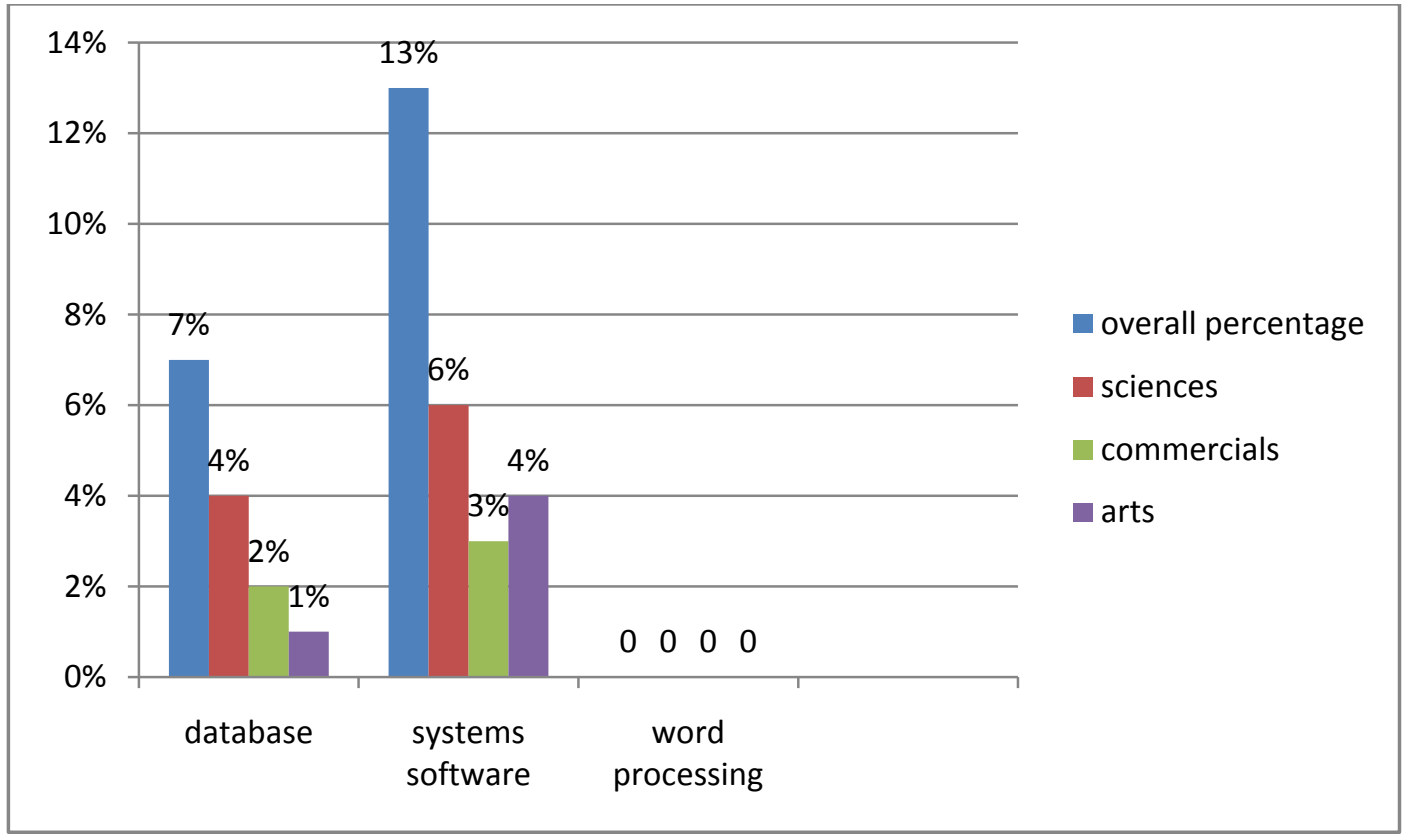

Fig. 10. Level of competence of students when asked various software questions

As shown in Fig. 10 above the questions proved to be too difficult for the students. The graph also proves that those majoring in sciences are better "technology wise" than their counterparts majoring in commerce and arts. When these students are deployed to their future schools they will not use technology in their classes because they lack the skills as evidenced by the graph.

The final section of the questionnaire was testing the hardware skills of lecturers and students. Fig. 11 below shows the statistics of how they performed. 


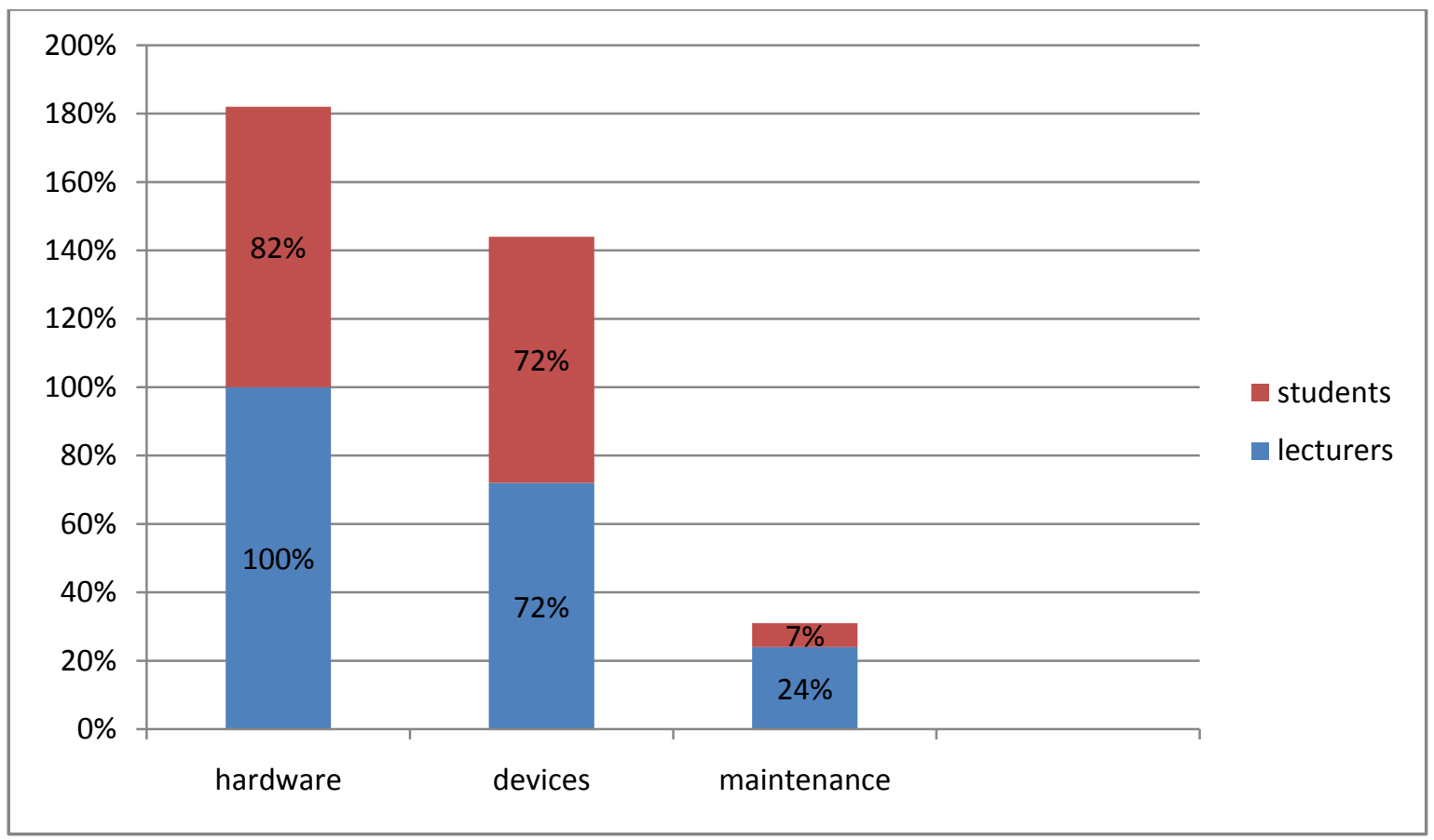

Fig. 11. Hardware skills for respondents

Both lecturers and students can identify pieces of hardware but they do not know how to maintain the equipment. If they face hardware problems during lectures they will need a

\section{CONCLUSION}

ICTs provide powerful tools that transform the current isolated teacher centered environment into rich student focused interactive environment. Most researchers are of the view that ICTs in education improve the quality of education, knowledge dissemination, effective learning, provides efficient education services, and will enable the institution to produce competitive and more enthusiastic students. The respondents to this research agree to these sentiments.

The Delta State University and most universities in the developing world, is still in the early stages of ICT adoption and is currently facing a lot of challenges. From the results obtained, the main obstacles hindering the integration of ICTs in teacher education programs in the university include:

- $\quad$ Lack of ICT infrastructure ( hardware, software and computer rooms)

- $\quad$ Lack of administration support

- $\quad$ Lack of finance

- Unskilled personnel

- Resistance from members of staff

- $\quad$ Lack of confidence in lecturers

- Government policies

- Lack of awareness of the benefits ICTs will bring to the department

The adoption of ICTs in the Delta State University requires careful planning and initiatives from the department's and university's administration. One major benefit that can be achieved from the use of ICTs is better simulations where students model real life scenarios using technology. This will technician or they will have to stop the lesson. This proves that training is needed for the successful integration of ICTs.

help the students when faced with those situations in the workplace.

From the results obtained, it can be concluded that most of the lecturers have a desire to integrate ICTs but they are faced with a lot of challenges amongst which are: lack of access to resources, lack of skills and confidence, and lack of infrastructure. Most of the barriers are interdependent such that alleviating one barrier is not enough to make the integration successful. The presence of all ICT components increases the likelihood of excellent integration of ICT in learning and teaching opportunities. Without ensuring proper ICT facility for the university students who are considered the future of the nation, they will not be able to fit into this current technology environment.

\section{REFERENCES}

[1] Anderson, J (2002). Integrating ICT and other technologies in teacher education: Trends, Issues and Guiding Principles. InforShare: Sources and

Resources bulletin. educationcarribean.com/edocs/ (Accessed 13-09-2012).

[2] Dede, C (1995). The Evolution of Constructivist Learning Environment: Immersion in Distributed, Virtual Worlds. Educational Technology, 35(5), 46-52.

[3] Goktas Y, Yildirim S, Yaildirim Z. Main barriers and possible enablers Integration into Pre-Service teacher education programs. Educational technology and Society, 12(1), 193-204.

[4] Jung, I (2005). ICT- Pedagogy integration in Teacher training: application cases worldwide. Educational and Technology Society, 8(2), 94-101.

[5] Khalid, A.B (2009). Barriers to the successful integration of ICT in teaching and learning environments: A review of the literature. Eurasia journal of mathematics, science and education, 5(3), 239-245. 
[6] Mehra P \& Mittal M (2007). Integrating technology into teaching-learning transaction: Pedagogical and technological perceptions of management faculty. International journal of Education and development using information and communication technology, 3(1), 105-115.

[7] Nafiz, Z, S (2010). Integrating ICT into University Curriculum: A proposal for the faculty of Arts university of Dhaka Bangladesh. In proceedings of Information Science and IT Education Conference (InSITE), 19-24 june, Italy.

[8] Nicholson. Integrating ICT into pre-service teacher education programs: Challenge and response.http://www.isatt.org/ISATT-papers/ISATT-

papers/Nicholson__ntegratingICTintopre serviceteachereducationprograms.pdf. (Accessed 15-032012)

[9] Ron, O (2002). The Role of ICT in higher education for the $21^{\text {st }}$ Century: ICT as a change agent for Higher Education. In proceedings of the Higher Education for the $21^{\text {st }}$ Century Conference, 24-26 September 2003, Curtin, Australia.

[10] Singh G \& Kaur G. (2004). Integration of ICT in Teacher Education. http://developmentcommunity.csdi.org/profiles/blogs/integration-of-ict-in-teacher-1 (Accessed 08-11-2012).

[11] Strydom, W.S. Thompson, J. Understanding ICT integration in South African Classrooms. SchoolNet SA research and evaluation.

[12] Tinio, V.L. (2003). ICT in education. United Nations Development Report, 6, 1-34.

[13] 